\title{
Tailoring Amine-Functionalized Ti-MOFs via a Mixed Ligands Strategy for High-Efficiency $\mathrm{CO}_{2}$ Capture
}

\author{
Yinji Wan ${ }^{1,+}$, Yefan Miao ${ }^{1,+}$, Tianjie Qiu ${ }^{2}$, Dekai Kong ${ }^{1}$, Yingxiao $\mathrm{Wu}^{2}$, Qiuning Zhang ${ }^{1}$, Jinming Shi ${ }^{2}$, \\ Ruiqin Zhong ${ }^{1, *}$ and Ruqiang Zou ${ }^{2, *}$ \\ 1 State Key Laboratory of Heavy Oil Processing, China University of Petroleum-Beijing, No. 18 Fuxue Road, \\ Changping District, Beijing 102249, China; wanyinji0613@163.com (Y.W.); 18332751996@163.com (Y.M.); \\ kongdekai6@163.com (D.K.); 13180275342@163.com (Q.Z.) \\ 2 Beijing Key Laboratory for Theory and Technology of Advanced Battery Materials, School of Materials \\ Science and Engineering, Peking University, No. 5 Yiheyuan Road, Haidian District, Beijing 100871, China; \\ qtjie@pku.edu.cn (T.Q.); yingxiaowucup@163.com (Y.W.); jinmings@pku.edu.cn (J.S.) \\ * Correspondence: zhong2004@foxmail.com (R.Z.); rzou@pku.edu.cn (R.Z.) \\ + These authors contributed equally to this work.
}

\section{check for} updates

Citation: Wan, Y.; Miao, Y.; Qiu, T.; Kong, D.; Wu, Y.; Zhang, Q.; Shi, J.;

Zhong, R.; Zou, R. Tailoring

Amine-Functionalized Ti-MOFs via a

Mixed Ligands Strategy for

High-Efficiency $\mathrm{CO}_{2}$ Capture.

Nanomaterials 2021, 11, 3348. https://

doi.org/10.3390/nano11123348

Academic Editors: Federico Cesano,

Mohammed Jasim Uddin and

Simas Rackauskas

Received: 8 November 2021

Accepted: 7 December 2021

Published: 10 December 2021

Publisher's Note: MDPI stays neutral with regard to jurisdictional claims in published maps and institutional affiliations.

Copyright: (c) 2021 by the authors. Licensee MDPI, Basel, Switzerland. This article is an open access article distributed under the terms and conditions of the Creative Commons Attribution (CC BY) license (https:// creativecommons.org/licenses/by/ $4.0 /)$.

\begin{abstract}
Amine-functionalized metal-organic frameworks (MOFs) are a promising strategy for the high-efficiency capture and separation of $\mathrm{CO}_{2}$. In this work, by tuning the ratio of 1,3,5benzenetricarboxylic acid $\left(\mathrm{H}_{3} \mathrm{BTC}\right)$ to 5-aminoisophthalic acid (5- $\left.\mathrm{NH}_{2}-\mathrm{H}_{2} \mathrm{IPA}\right)$, we designed and synthesized a series of amine-functionalized highly stable Ti-based MOFs (named MIP-207-NH ${ }_{2}-n$, in which $n$ represents $15 \%, 25 \%, 50 \%, 60 \%$, and $100 \%$ ). The structural analysis shows that the original framework of MIP-207 in the MIP-207- $\mathrm{NH}_{2}-n(n=15 \%, 25 \%$, and 50\%) MOFs remains intact when the mole ratio of ligand $\mathrm{H}_{3}$ BTC to $5-\mathrm{NH}_{2}-\mathrm{H}_{2}$ IPA is less than 1 to 1 in the resulting MOFs. By the introduction of amino groups, MIP-207- $\mathrm{NH}_{2}-25 \%$ demonstrates outstanding $\mathrm{CO}_{2}$ capture performance up to 3.96 and $2.91 \mathrm{mmol} \mathrm{g}^{-1}, 20.7 \%$ and $43.3 \%$ higher than those of unmodified MIP-207 at 0 and $25{ }^{\circ} \mathrm{C}$, respectively. Furthermore, the breakthrough experiment indicates that the dynamic $\mathrm{CO}_{2}$ adsorption capacity and $\mathrm{CO}_{2} / \mathrm{N}_{2}$ separation factors of MIP-207- $\mathrm{NH}_{2}-25 \%$ are increased by about $25 \%$ and $15 \%$, respectively. This work provides an additional strategy to construct amine-functionalized MOFs with the maintenance of the original MOF structure and high performance of $\mathrm{CO}_{2}$ capture and separation.
\end{abstract}

Keywords: Ti-MOFs; amine functionalization; $\mathrm{CO}_{2}$ capture; separation; breakthrough experiment

\section{Introduction}

More than $85 \%$ of the worldwide energy demand is provided by the combustion of fossil fuels [1,2], but at the cost of considerable $\mathrm{CO}_{2}\left(3 \times 10^{13} \mathrm{~kg} \mathrm{CO}_{2}\right.$ per year $)$ being emitted into the atmosphere, thus leading to the daunting greenhouse effect [3-5]. The carbon capture and storage/sequestration (CCS) technology therefore has been proposed to mitigate emissions of atmospheric $\mathrm{CO}_{2}$. For CCS technology, the breakthrough of novel adsorbents with a large $\mathrm{CO}_{2}$ working capacity as well as a high $\mathrm{CO}_{2}$ selectivity and easy regeneration is the core [6-8].

Metal-organic frameworks (MOFs) have been widely used for various applications owing to their ordered crystallinity, high specific surface area, and versatile tunability of chemical environments [9-17]. In particular, they can serve as attractive platforms for $\mathrm{CO}_{2}$ adsorption and separation to mitigate the greenhouse effect [18-25]. It is widely acknowledged that amine-functionalized MOFs are one of the most effective ways to capture $\mathrm{CO}_{2}$, because this method has the advantages of a large working $\mathrm{CO}_{2}$ capacity as well as a high $\mathrm{CO}_{2}$ selectivity and a low energy penalty for regeneration $[7,26]$. Currently, many MOF materials have been functionalized by the direct synthesis or post-synthesis modification method to graft amine [27-30]. For example, Kim et al. [28] prepared a robust tetraamine-functionalized $\mathrm{Mg}-\mathrm{MOF}$ by the post-synthesis strategy. The tetraaminefunctionalized framework showed an excellent $\mathrm{CO}_{2}$ trapping efficiency under low $\mathrm{CO}_{2}$ 
partial pressure in the flue stream. Han et al. [31] used a one-step hydrothermal method to synthesize MIL-101(Cr)- $\mathrm{NH}_{2}$ nanoparticles. Compared with MIL-101(Cr), the $\mathrm{CO}_{2}$ adsorption capacity of MIL-101(Cr)- $\mathrm{NH}_{2}$ increased from 1.85 to $2.25 \mathrm{mmol} \mathrm{g}^{-1}$. Moreover, the separation factor of $\mathrm{CO}_{2} / \mathrm{N}_{2}$ was enhanced from 7.5 to 11.6 at $1 \mathrm{~atm}$ and $35^{\circ} \mathrm{C}$. Recently, Zhong et al. [32] introduced three kinds of organic amine molecules into the channels of MIL-101(Cr) by the post-modification method. The results showed that the $\mathrm{CO}_{2} / \mathrm{CO}$ selectivity of the Tris(2-aminoethyl) amine-modified MIL-101 was 103 times higher than that of its pure MIL-101 counterpart.

In this work, the MIP-207, fabricated by Ti-O clusters and the $\mathrm{H}_{3} \mathrm{BTC}$ ligand [21,33], was selected as the porous material, mainly due to its large specific surface area and high chemical stability even in highly acidic media $(\mathrm{pH} \leq 0)$. More importantly, there are uncoordinated and isolated - $\mathrm{COOH}$ groups toward the channels of MIP-207 because of the meta-connection mode of the $\mathrm{H}_{3}$ BTC ligand, so the chemical environment of MIP-207 cavities can be easily modulated by the mixed linkers strategy [33]. There are quite a few reports on amine-grafted highly stable MIP-207 for highly efficient $\mathrm{CO}_{2}$ capture [33]. Additionally, the accurate grafting of amine molecules without any framework destruction of the host frameworks is less of a concern. Herein, we for the first time prepared a series of amine-functionalized highly stable MIP-207 materials and further tailored the content of $-\mathrm{NH}_{2}$ by the mixed linkers strategy for capturing $\mathrm{CO}_{2}$ from $\mathrm{N}_{2}$. It should be pointed out that amine-functionalized MIP-207 materials cannot be obtained when the mole ratio of $\mathrm{H}_{3}$ BTC to $5-\mathrm{NH}_{2}-\mathrm{H}_{2} \mathrm{IPA}$ exceeds 1 (See Figure 1). The physiochemical properties of the as-prepared materials were systematically characterized and analyzed, and the $\mathrm{CO}_{2}$ adsorption and separation were also investigated. Based on the excellent $\mathrm{CO}_{2}$ capture performance of MIP-207- $\mathrm{NH}_{2}-25 \%$, the breakthrough experiments further evaluated the dynamic adsorption capacity and separation factors under different gas flow rates.

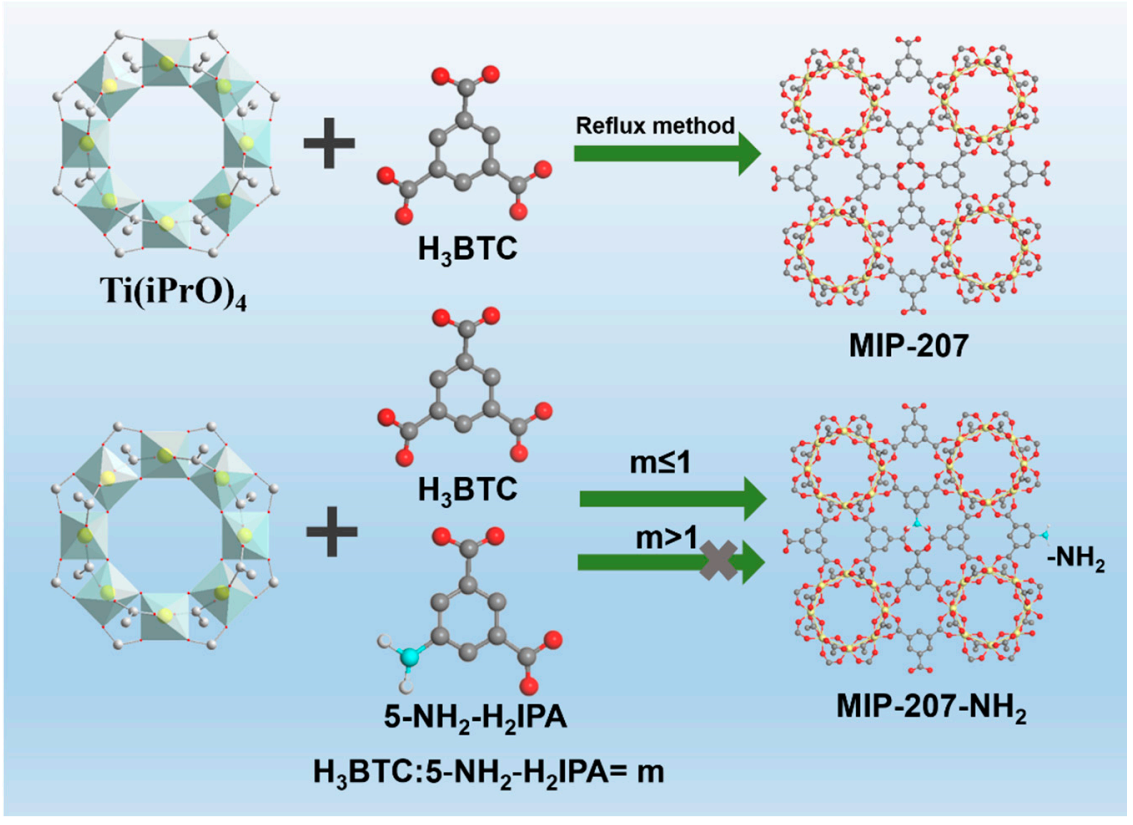

Figure 1. Schematic Diagram of MIP-207 and amine-functionalized MIP-207; Ti is shown in yellow, $\mathrm{C}$ in gray, $\mathrm{O}$ in red, $\mathrm{N}$ in light blue, and $\mathrm{H}$ in white.

\section{Experimental Section}

2.1. Synthesis of MIP-207

All the reagents used were commercially purchased without further purification. MIP207 was synthesized in a similar method to the one reported [33]. 1,3,5-benzenetricarboxylic acid $\left(\mathrm{H}_{3} \mathrm{BTC}\right)$, acetic acid, and acetic anhydride were purchased from Maclin, Shanghai, China. Tetraisopropyl titanate was purchased from Sinopharm Chemical Reagent Co., Ltd., 
Beijing, China. $\mathrm{H}_{3}$ BTC (840 mg, $\left.4 \mathrm{mmol}\right)$, acetic acid $(10 \mathrm{~mL})$ and acetic anhydride $(10 \mathrm{~mL})$ were added and mixed into a $50 \mathrm{~mL}$ round-bottom flask at ambient temperature. Then, tetraisopropyl titanate $(800 \mu \mathrm{L}, 2.7 \mathrm{mmol})$ was added under stirring. The mixture was refluxed at $120{ }^{\circ} \mathrm{C}$ for $12 \mathrm{~h}$. After cooling to room temperature, the crude product was separated and washed with boiling anhydrous acetone. Finally, the product was collected by centrifugation and placed in an $80^{\circ} \mathrm{C}$ oven for $12 \mathrm{~h}$.

\subsection{Synthesis of Amine-Functionalized MIP-207}

The amine-functionalized MIP-207 was prepared with a pre-synthesis modification method. Part of the $\mathrm{H}_{3}$ BTC ligand was replaced with a certain amount of 5- $\mathrm{NH}_{2}-\mathrm{H}_{2} \mathrm{IPA}$, which accounted for $15 \%, 25 \%, 50 \%, 60 \%$, and $100 \%$ of the total $\mathrm{H}_{3} \mathrm{BTC}$, respectively. A series of amine-functionalized MIP-207 materials were synthesized according to the above synthetic steps of MIP-207, and the as-prepared materials were denoted as MIP$207-\mathrm{NH}_{2}-n(n=15 \%, 25 \%, 50 \%, 60 \%$, and $100 \%)$, respectively. It must be pointed out that the structure of MIP-207- $\mathrm{NH}_{2}-100 \%$ is completely different from that of MIP-207; it is still named MIP-207- $\mathrm{NH}_{2}-100 \%$ simply for the purpose of comparison.

\subsection{Sample Characterization}

Powder X-ray diffraction (PXRD) patterns of the samples were recorded on a Rigaku $\mathrm{D} / \max 2400 \mathrm{X}$-ray diffractometer equipped with $\mathrm{Cu} \mathrm{K} \alpha$ radiation operating at $45 \mathrm{kV}$ and $200 \mathrm{~mA}$. Scanning electron microscopy (SEM) tests were conducted on a Hitachi S4800 electron microscope to observe the morphologies of the samples. A $\mathrm{N}_{2}$ physisorption test was carried out on a Quantachrome Autosorb-iQ (Quantachrome Instruments, Boynton Beach, FL, USA) at $-196^{\circ} \mathrm{C}$. The elemental analysis (EA) of the samples was performed on an Elementar Analysensysteme GmbH Vario EL (Analytical Instrumentation Department of the Heraeus technology group, Frankfurt, Germany) analyzer to accurately analyze the percentage content of the $\mathrm{C}, \mathrm{H}$, and $\mathrm{N}$ elements of samples. The specific surface area of the samples was analyzed according to the Brunauer-Emmett-Teller (BET) method and pore size distribution was calculated using the non-local density functional theory (NLDFT) model.

\subsection{Gas Adsorption Measurements}

All the gases $\left(\mathrm{N}_{2}\right.$ and $\left.\mathrm{CO}_{2}\right)$ used were of ultrahigh purity (99.999\%) in this study. $\mathrm{N}_{2}$ and $\mathrm{CO}_{2}$ adsorption isotherms were measured by a Quantachrome Autosorb-iQ gas adsorption analyzer up to $1 \mathrm{bar}$, and the temperatures of 0 and $25^{\circ} \mathrm{C}$ were both maintained with an ethylene glycol $/ \mathrm{H}_{2} \mathrm{O}$ bath by a cooling and heating system. Before the measurement, about $100 \mathrm{mg}$ of the adsorbent was degassed at $150{ }^{\circ} \mathrm{C}$ for $8 \mathrm{~h}$ in vacuum condition. The adsorption and desorption of $\mathrm{CO}_{2}$ cyclic stability was carried out on an SDT Q600 analyzer (TA Instruments, New Castle, DE, USA). Firstly, the sample fully absorbed $\mathrm{CO}_{2}$ at $35{ }^{\circ} \mathrm{C}$ for $1 \mathrm{~h}$, and then it was injected with $\mathrm{N}_{2}$ gas at $150{ }^{\circ} \mathrm{C}$ for $2 \mathrm{~h}$. The breakthrough experiments were performed on a homemade setup to simulate the actual mixture gas (20 vol\% $\mathrm{CO}_{2}, 20 \mathrm{vol} \% \mathrm{~N}_{2}$, and balanced gas $\mathrm{He}$ ) separation to evaluate the dynamic $\mathrm{CO}_{2} / \mathrm{N}_{2}$ adsorption performance; the setup diagram of the breakthrough experiment can be found in our previous work [34].

\section{Results and Discussion}

\subsection{Structural Analysis of Samples}

As shown in Figure S1, compared with simulated MIP-207, the characteristic diffraction peak positions and relative intensities of MIP-207 after reflux treatment at $120{ }^{\circ} \mathrm{C}$ for $12 \mathrm{~h}$ fit very well, illustrating that MIP-207 with a high purity was synthesized. Also, Figure S1 exhibits that the structure of MIP-207 was maintained well after activation at $150{ }^{\circ} \mathrm{C}$. To evaluate the influence of the content of $-\mathrm{NH}_{2}$ on the crystal structure of MIP-207, the PXRD patterns of MIP-207- $\mathrm{NH}_{2}$ were obtained, and the results are shown in Figure 2. The comparison of PXRD patterns among 207- $\mathrm{NH}_{2}-n(n=0,15 \%, 25 \%, 50 \%)$ supported 
that they were of the same pure phase. However, the internal crystal structure of the amine-modified MIP-207 composites started to change when the mole ratio of $\mathrm{H}_{3} \mathrm{BTC}$ to $5-\mathrm{NH}_{2}-\mathrm{H}_{2} \mathrm{IPA}$ was more than 1 . As shown in Figure 2, there were still two characteristic diffraction peaks of $5^{\circ}$ and $11.5^{\circ}$ in the MIP-207- $\mathrm{NH}_{2}-60 \%$, but peak relative intensities were significantly reduced, showing that most of the crystal structure of MIP-207 in the composites was changed. When the ligand $\mathrm{H}_{3} \mathrm{BTC}$ was totally replaced by $5-\mathrm{NH}_{2}-\mathrm{H}_{2} \mathrm{IPA}$, the characteristic diffraction peaks (Figure S2) of the sample were totally different from those of the original MIP-207, indicating that another crystalline phase was formed due to the transformation of the coordination mode.

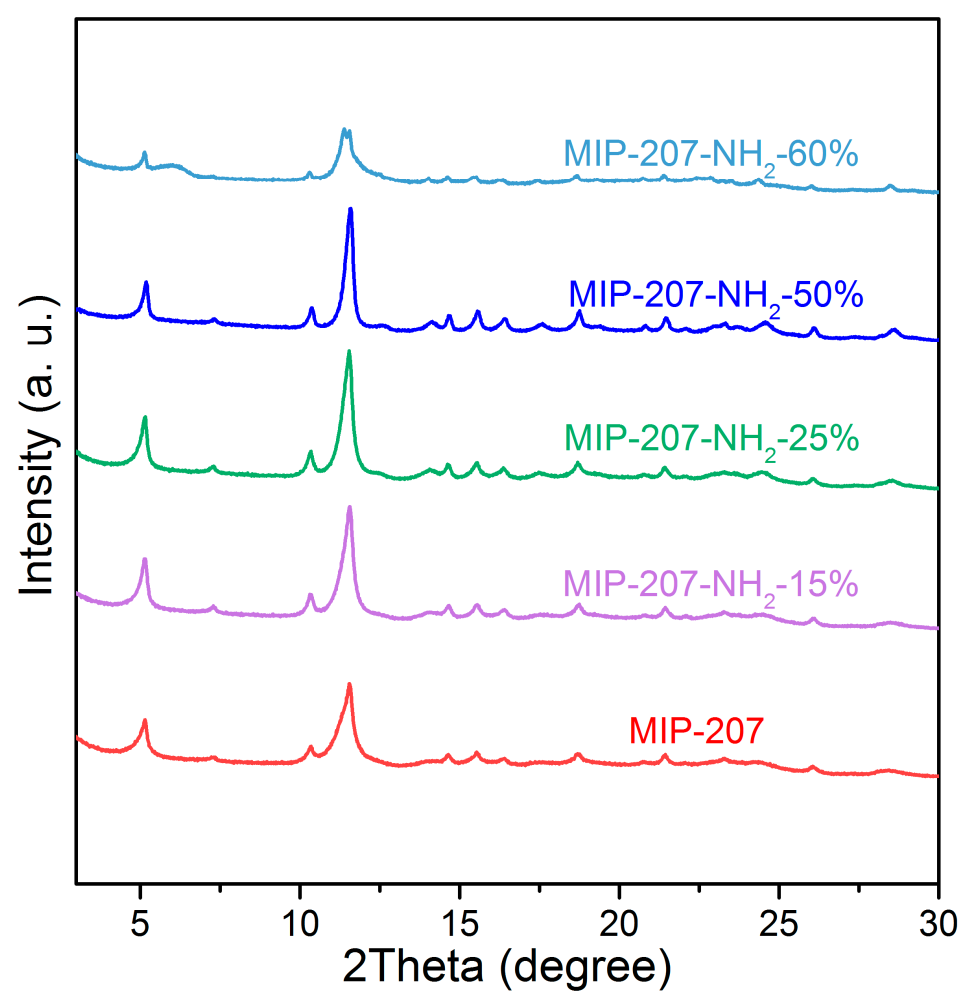

Figure 2. PXRD pattern of samples.

The SEM images of pristine MIP-207 are presented in Figure S3a,b, and the stacked nanoparticles with a size range of $20-25 \mathrm{~nm}$ can be observed. As shown in Figure S3c-e, as the amount of exchange ligand $5-\mathrm{NH}_{2}-\mathrm{H}_{2} \mathrm{IPA}$ increases, the stacking of nanoparticles becomes loose, and the particle size was also in the range of $20-25 \mathrm{~nm}$ in the MIP-207- $\mathrm{NH}_{2}$ $n(n=15 \%, 25 \%, 50 \%)$ composites, which is consistent with XRD results obtained by the Scherrer equation (Table 1). However, the original morphology of MIP-207 is basically not observed in the MIP-207- $\mathrm{NH}_{2}-60 \%$ (Figure S3f), and particle size sharply reduced to about $15 \mathrm{~nm}$. Overall, based on the above PXRD and SEM analysis, the crystal structure and texture of MIP-207 in the amine-modified MIP-207 composites can be maintained with the amount of added $5-\mathrm{NH}_{2}-\mathrm{H}_{2} \mathrm{IPA}$ being less than or equal to $50 \%$.

As shown in Table 1, the $\mathrm{N}$ element was not found in the parent MIP-207. The $\mathrm{N}$ element was detected and the $\mathrm{N}$ content of the amine-modified MIP-207 composites increased with the increase of the added 5- $\mathrm{NH}_{2}-\mathrm{H}_{2}$ IPA ligand, demonstrating that $-\mathrm{NH}_{2}$ was introduced into the framework of MIP-207 through a mixed linkers strategy. Notably, Table 1 indicates that the N element content in the MIP-207- $\mathrm{NH}_{2}-n(n=15 \%, 25 \%, 50 \%)$ composites was lower than the theoretical value, which is attributed to the electronic effect of the functional group of the ligand. Generally, the electron-donating groups such as $-\mathrm{NH}_{2}$, $-\mathrm{OH}$, and $-\mathrm{CH}_{3}$ are difficult to connect with the second building units of MIP-207 [33]. The theoretical N content of MIP-207- $\mathrm{NH}_{2}-100 \%$ is $3.54 \%$. This value is close to the actual value, while the structure completely changed according to the PXRD results. 
Table 1. The content of $\mathrm{C}, \mathrm{H}$, and $\mathrm{N}$ elements of samples and particle size obtained by Scherrer equation.

\begin{tabular}{cccccc}
\hline Samples & C (\%) & H (\%) & $\begin{array}{c}\text { The Actual } \\
\text { N (\%) }\end{array}$ & $\begin{array}{c}\text { The Theoretical } \\
\text { N (\%) }\end{array}$ & $\begin{array}{c}\text { Particle } \\
\text { Size (nm) }\end{array}$ \\
\hline MIP-207 & 35.37 & 2.91 & 0 & 0 & 21.9 \\
MIP-207-NH $-15 \%$ & 35.46 & 2.76 & 0.19 & 0.47 & 22.3 \\
MIP-207-NH $-25 \%$ & 35.03 & 2.72 & 0.26 & 0.83 & 23.6 \\
MIP-207-NH $-50 \%$ & 35.07 & 2.89 & 0.45 & 1.70 & 28.4 \\
MIP-207-NH $-20 \%$ & 35.11 & 3.04 & 0.93 & 2.06 & 15.5 \\
MIP-207-NH $-100 \%$ & 41.48 & 3.99 & 3.24 & 3.54 & - \\
\hline
\end{tabular}

Note: The theoretical value of the $\mathrm{N}$ element is calculated assuming that $5-\mathrm{NH}_{2}-\mathrm{H}_{2} \mathrm{IPA}$ completely reacts.

The results of the measurement of $\mathrm{N}_{2}$ adsorption and desorption isotherms are shown in Figure 3 and Table 2, and the $\mathrm{N}_{2}$ adsorption-desorption curves of MIP-207 (Figure 3) conform to the typical I-type isotherm characteristics in the low-pressure zone $(0-0.6 \mathrm{~atm})$ relating to microporous characteristics [35]. With the increase of pressure, there was a hysteresis loop in the adsorption-desorption curves, indicating the existence of mesopores, which may be caused by the accumulation of materials. The specific surface area of MIP-207 was $563 \mathrm{~m}^{2} \mathrm{~g}^{-1}$, where the specific surface area was mainly micropores $\left(534 \mathrm{~m}^{2} \mathrm{~g}^{-1}\right)$, which confirms that the mesopores are caused by stacked pores. Figure S4 shows that the average pore size of MIP-207 was mainly distributed at 0.57 and $0.82 \mathrm{~nm}$. Obviously, the BET area and pore volume of the MIP-207- $\mathrm{NH}_{2}-n(n=15 \%, 25 \%, 50 \%)$ materials were higher than that of the unmodified MIP-207 (Table 2), mainly because the mass and volume of the $-\mathrm{NH}_{2}$ group is smaller than the -COOH group, so the BET area of MIP-207- $\mathrm{NH}_{2}-n(n=15 \%, 25 \%$, $50 \%$ ) increased. Among them, the BET area of MIP-207- $\mathrm{NH}_{2}-25 \%$ was the highest, reaching $735 \mathrm{~m}^{2} \mathrm{~g}^{-1}$. On the contrary, the BET area of MIP-207- $\mathrm{NH}_{2}-60 \%$ reduced in comparison with MIP-207. In addition, compared with the MIP-207- $\mathrm{NH}_{2}-n(n=15 \%, 25 \%, 50 \%)$ (Table 2), the pore volume of MIP-207- $\mathrm{NH}_{2}-60 \%\left(0.44 \mathrm{~cm}^{3} \mathrm{~g}^{-1}\right)$ decreased. The probable reason is that the original structure of MIP-207 cannot be maintained with the $-\mathrm{NH}_{2}$ increasing to over $60 \%$. The specific surface area of MIP-207- $\mathrm{NH}_{2}-100 \%$ sharply decreased and the micropores almost disappeared (Figure S5 and Table S1), further demonstrating the changes from the MIP-207 framework in MIP-207- $\mathrm{NH}_{2}-100 \%$.

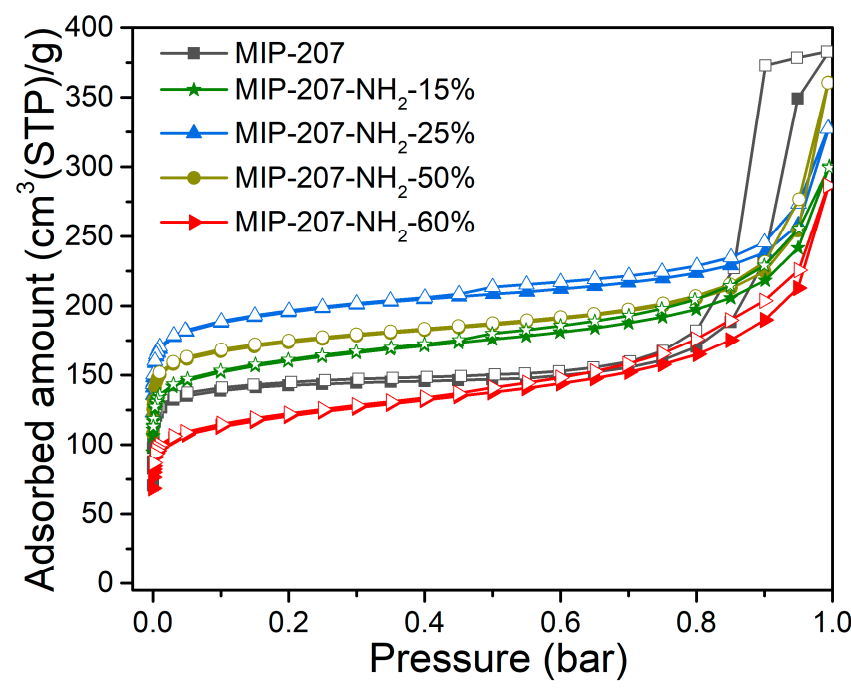

Figure 3. $\mathrm{N}_{2}$ adsorption and desorption isotherms at $-196^{\circ} \mathrm{C}$. 
Table 2. The summary of specific surface area, pore volume, and particle size of samples.

\begin{tabular}{|c|c|c|c|c|}
\hline Samples & $\begin{array}{l}\text { BET Area } \\
\left(\mathrm{m}^{2} \mathrm{~g}^{-1}\right)\end{array}$ & $\begin{array}{c}\text { Micropore } \\
\text { Area }\left(\mathrm{m}^{2} \mathrm{~g}^{-1}\right)\end{array}$ & $\begin{array}{c}\text { Total Pore } \\
\text { Volume }\left(\mathrm{cm}^{3} \mathrm{~g}^{-1}\right)\end{array}$ & $\begin{array}{c}\text { Micropore } \\
\text { Volume }\left(\mathrm{cm}^{3} \mathrm{~g}^{-1}\right)\end{array}$ \\
\hline MIP-207 & 563 & 534 & 0.36 & 0.21 \\
\hline MIP-207-NH $2-15 \%$ & 576 & 468 & 0.46 & 0.20 \\
\hline MIP-207-NH $2-25 \%$ & 735 & 659 & 0.51 & 0.27 \\
\hline MIP-207-NH $-50 \%$ & 654 & 569 & 0.56 & 0.23 \\
\hline MIP-207-NH $-60 \%$ & 435 & 321 & 0.44 & 0.14 \\
\hline
\end{tabular}

\subsection{Gas Adsorption Performance of Materials}

The $\mathrm{CO}_{2}$ adsorption data of as-prepared materials over $\mathrm{N}_{2}$ are presented in Figure 4 and Table 3. As can be seen from Table 3, the $\mathrm{CO}_{2}$ adsorption capacity of MIP-207- $\mathrm{NH}_{2}-25 \%$ was up to 3.96 and $2.91 \mathrm{mmol} \mathrm{g}^{-1}$ at 0 and $25^{\circ} \mathrm{C}$, which means an improvement of $20.7 \%$ and $43.3 \%$ compared with the pure MIP-207, respectively. Moreover, the $\mathrm{CO}_{2}$ capture performance of MIP-207- $\mathrm{NH}_{2}-25 \%$ outperforms most reported amine-modified $\mathrm{MOF} \mathrm{CO}_{2}$ adsorbents (Table 3). Similarly, the $\mathrm{CO}_{2}$ adsorption capacity of MIP-207- $\mathrm{NH}_{2}-50 \%$ was higher than that of the unmodified MIP-207. The increase of $\mathrm{CO}_{2}$ adsorption capacity is mainly due to the amine-grafted MIP-207 materials with a high specific area (Figure S6) and many Lewis basic sites (LBS), which greatly enhance their affinity for $\mathrm{CO}_{2}[36,37]$. Unfortunately, as the added exchange ligand $5-\mathrm{NH}_{2}-\mathrm{H}_{2} \mathrm{IPA}$ went above $50 \%$, the $\mathrm{CO}_{2}$ working capacity in the MIP-207- $\mathrm{NH}_{2}-60 \%$ adsorbent sharply decreased. One reasonable explanation is that excess $5-\mathrm{NH}_{2}-\mathrm{H}_{2} \mathrm{IPA}$ slows down the rate of the crystal nucleation formation of MIP-207 and disturbs the self-assembly process. When the ligand reactant is completely $5-\mathrm{NH}_{2}-\mathrm{H}_{2} \mathrm{IPA}$, the resulting product cannot even form the original crystal nucleus structure of MIP-207. It can be seen that the adsorption performance is a result of both the adsorption sites and the spatial framework of materials.

Table 3. The summary of BET area and $\mathrm{CO}_{2}$ adsorption results in this work and reported amine-functionalized MOFs.

\begin{tabular}{|c|c|c|c|c|c|}
\hline Materials & $\begin{array}{l}\text { Surface Area } \\
\left(\mathrm{m}^{2} \mathrm{~g}^{-1}\right)\end{array}$ & $\mathrm{CO}_{2}$ Uptake at Testing Condition & $\begin{array}{l}\mathrm{CO}_{2} / \mathrm{N}_{2}(\mathrm{CO}) \\
\text { Selectivity }\end{array}$ & $Q_{\text {st }}\left(\mathrm{kJ} \mathrm{mol}^{-1}\right)$ & Ref. \\
\hline MIP-207 & 563 & $\begin{array}{c}3.28 / 2.03 \mathrm{mmol} \mathrm{g}^{-1} @ 0 / 25^{\circ} \mathrm{C} \text { and } \\
1 \text { bar }\end{array}$ & 59 & - & This work \\
\hline MIP-207-NH $2-15 \%$ & 576 & $\begin{array}{c}3.12 / 2.21 \mathrm{mmol} \mathrm{g}^{-1} @ 0 / 25^{\circ} \mathrm{C} \text { and } \\
1 \text { bar }\end{array}$ & - & $30-35$ & This work \\
\hline MIP-207-NH ${ }_{2}-25 \%$ & 735 & $\begin{array}{c}3.96 / 2.91 \mathrm{mmol} \mathrm{g}^{-1} @ 0 / 25^{\circ} \mathrm{C} \text { and } \\
1 \text { bar }\end{array}$ & 77 & $30-35$ & This work \\
\hline MIP-207-NH $2-50 \%$ & 654 & $\begin{array}{c}3.49 / 2.36 \mathrm{mmol} \mathrm{g}^{-1} @ 0 / 25^{\circ} \mathrm{C} \text { and } \\
1 \text { bar }\end{array}$ & - & $30-35$ & This work \\
\hline MIP-207-NH ${ }_{2}-60 \%$ & 435 & $\begin{array}{c}2.02 / 1.04 \mathrm{mmol} \mathrm{g}^{-1} @ 0 / 25^{\circ} \mathrm{C} \text { and } \\
1 \text { bar }\end{array}$ & - & $30-35$ & This work \\
\hline ZIF-8 (40) & 844 & $0.11 \mathrm{mmol} \mathrm{g}^{-1} @ 45^{\circ} \mathrm{C}$ and $0.15 \mathrm{bar}$ & - & 55 & [19] \\
\hline $\mathrm{ED} @ \mathrm{Cu}_{3}(\mathrm{BTC})_{2}-1$ & 444 & $\begin{array}{c}4.28 / 2.15 \mathrm{mmol} \mathrm{g}^{-1} @ 0 / 25^{\circ} \mathrm{C} \text { and } \\
1 \text { bar }\end{array}$ & 21.5 & 39 & [29] \\
\hline $\mathrm{ED} @ \mathrm{Cu}_{3}(\mathrm{BTC})_{2}-2$ & 163 & 1.03/0.54 $\mathrm{mmol} \mathrm{g}^{-1} @ 0 /$ and 1 bar & 2.68 & - & [29] \\
\hline MAF-23 & - & $2.5 \mathrm{mmol} \mathrm{g}{ }^{-1} @ 25^{\circ} \mathrm{C}$ and $1 \mathrm{bar}$ & 87 & $34.9 \pm 0.9$ & {$[38]$} \\
\hline ED@MIL-101 & 1584.6 & $\begin{array}{c}3.93 / 1.93 \mathrm{mmol} \mathrm{g}^{-1} @ 0 / 25^{\circ} \mathrm{C} \text { and } \\
1 \text { bar }\end{array}$ & 17.3 & - & {$[32]$} \\
\hline TEDA@MIL-101 & 1806.9 & $\begin{array}{c}3.81 / 1.65 \mathrm{mmol} \mathrm{g}^{-1} @ 0 / 25^{\circ} \mathrm{C} \text { and } \\
1 \mathrm{bar}\end{array}$ & 15.5 & - & [32] \\
\hline MIL-101(Cr)-NH $\mathrm{NH}_{2}$ & $2800 \pm 200$ & $3.4 \mathrm{mmol} \mathrm{g}-1 @ 15^{\circ} \mathrm{C}$ and 1 bar & 26.5 & 54.6 & [31] \\
\hline PM24@MOF & 2550 & $2.9 \mathrm{mmol} \mathrm{g}-1 @ 0 / 25^{\circ} \mathrm{C}$ and 1 bar & 84 & 84 & [39] \\
\hline R-PM24@MOF & 2410 & $3.6 \mathrm{mmol} \mathrm{g}-100 / 25^{\circ} \mathrm{C}$ and 1 bar & 143 & 50 & [39] \\
\hline
\end{tabular}



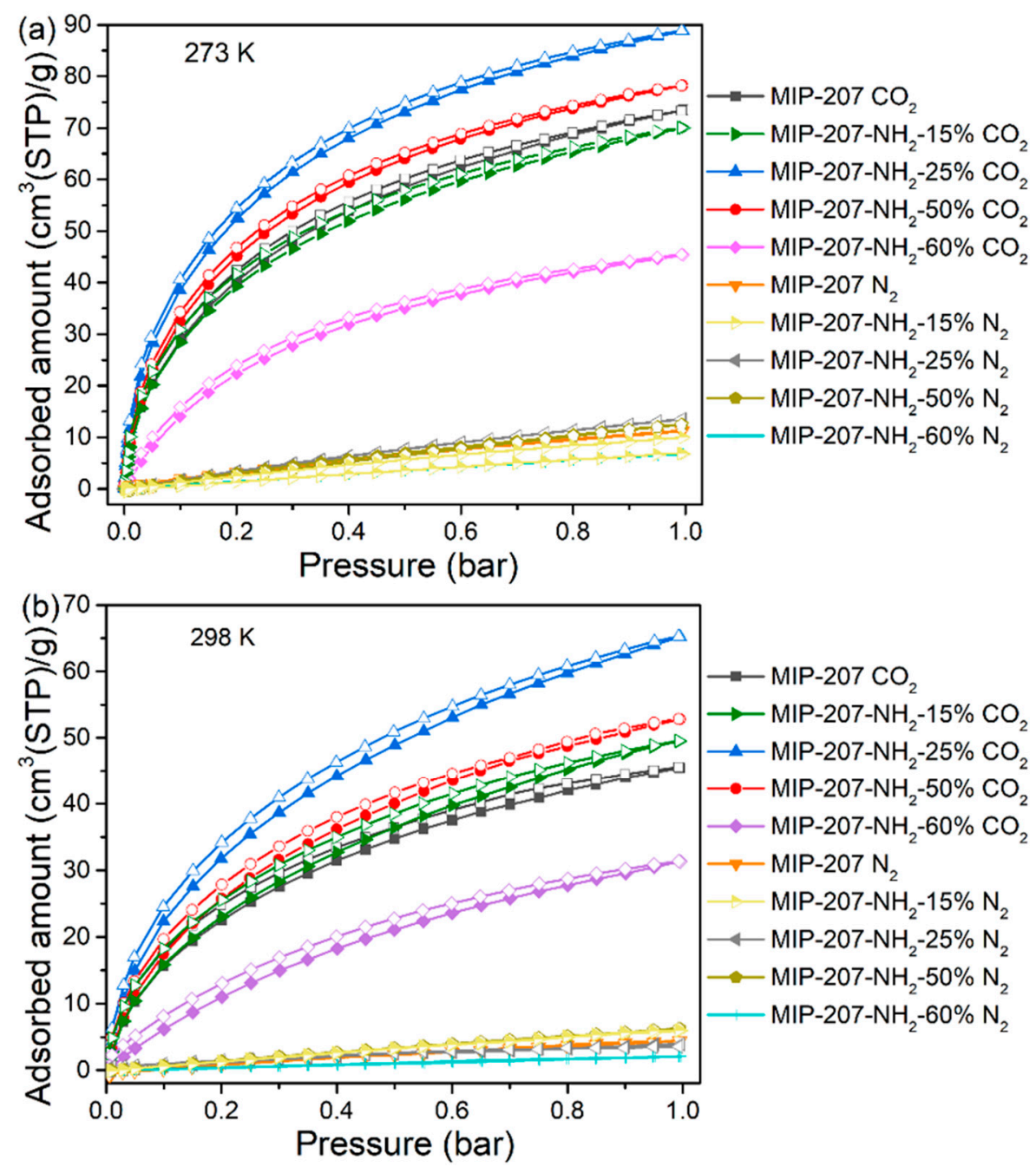

Figure 4. $\mathrm{CO}_{2}$ and $\mathrm{N}_{2}$ adsorption and desorption isotherms at $(\mathbf{a}) 0^{\circ} \mathrm{C}$ and (b) $25^{\circ} \mathrm{C}$.

To figure out the $\mathrm{CO}_{2}$ adsorption separation performance, the selectivity of $\mathrm{CO}_{2} / \mathrm{N}_{2}$ was calculated by the IAST model (Supporting Information). As shown in Figure 5a, compared with the separation factor of MIP-207 (59), the $\mathrm{CO}_{2} / \mathrm{N}_{2}$ separation factor of MIP-207- $\mathrm{NH}_{2}-15 \%$ was 69 , which was $17 \%$ higher than that of MIP-207. Additionally, MIP-207- $\mathrm{NH}_{2}-25 \%$ exhibited the highest $\mathrm{CO}_{2} / \mathrm{N}_{2}$ separation factor (77), which was $33 \%$ higher than MIP-207, mainly because the introduction of the $-\mathrm{NH}_{2}$ group into the MIP-207 channels could produce more adsorption sites, leading to an enhanced affinity toward $\mathrm{CO}_{2}$. However, the structure of MIP-207- $\mathrm{NH}_{2}-60 \%$ possessed more $-\mathrm{NH}_{2}$ and the separation factor of MIP-207- $\mathrm{NH}_{2}-60 \%$ was only 22, illustrating that the spatial framework of MIP207 in MIP-207- $\mathrm{NH}_{2}-60 \%$ was destroyed, thus increasing the non-selective uptake. In addition to focusing on the adsorption and separation performance, it is also necessary to take energy consumption into account during the regeneration process in industrial applications [32]. The isosteric heat of $\mathrm{CO}_{2}$ adsorption $\left(\mathrm{Q}_{\mathrm{st}}\right)$ of the materials was obtained from the $\mathrm{CO}_{2}$ adsorption isotherms at $0{ }^{\circ} \mathrm{C}$. As shown in Figure 5b, the MIP-207- $\mathrm{NH}_{2}-n$ $(n=15 \%, 25 \%, 50 \%)$ adsorbents had an isosteric adsorption heat of about $30-35 \mathrm{~kJ} \mathrm{~mol}^{-1}$, which exhibits a medium-strength interaction with $\mathrm{CO}_{2}$. It can also be found that the $\mathrm{Q}_{\mathrm{st}}$ of MIP-207- $\mathrm{NH}_{2}-60 \%$ was significantly lower than that of the above four materials, which indicates that the framework structure of MIP-207- $\mathrm{NH}_{2}-60 \%$ has a negative effect on the adsorption capacity of $\mathrm{CO}_{2}$. Considering that the MIP-207- $\mathrm{NH}_{2}-25 \%$ exhibited superior $\mathrm{CO}_{2}$ adsorption performance with a remarkable adsorption heat, a test of the cyclic stability of $\mathrm{CO}_{2}$ was performed and the results are displayed in Figure 6. The $\mathrm{CO}_{2}$ adsorption 
capacity of MIP-207- $\mathrm{NH}_{2}-25 \%$ after six cycles did not significantly decrease, indicating that MIP-207- $\mathrm{NH}_{2}-25 \%$ has an outstanding $\mathrm{CO}_{2}$ adsorption-desorption stability.
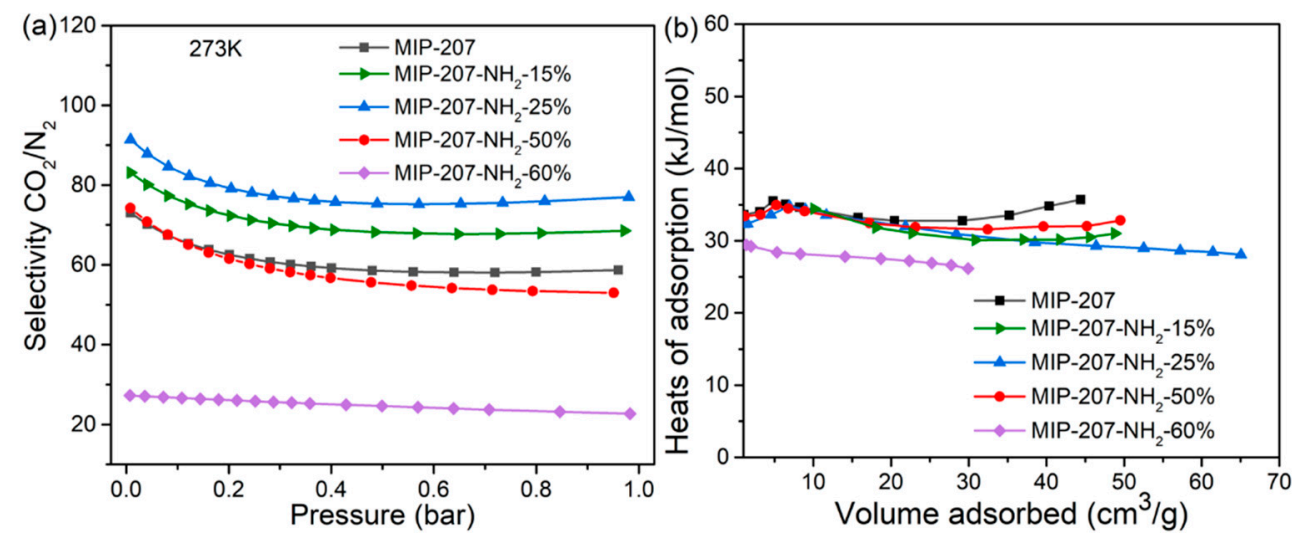

Figure 5. (a) $\mathrm{CO}_{2} / \mathrm{N}_{2}$ selectivity at $0{ }^{\circ} \mathrm{C}$ and (b) $\mathrm{CO}_{2}$ adsorption enthalpy curves.

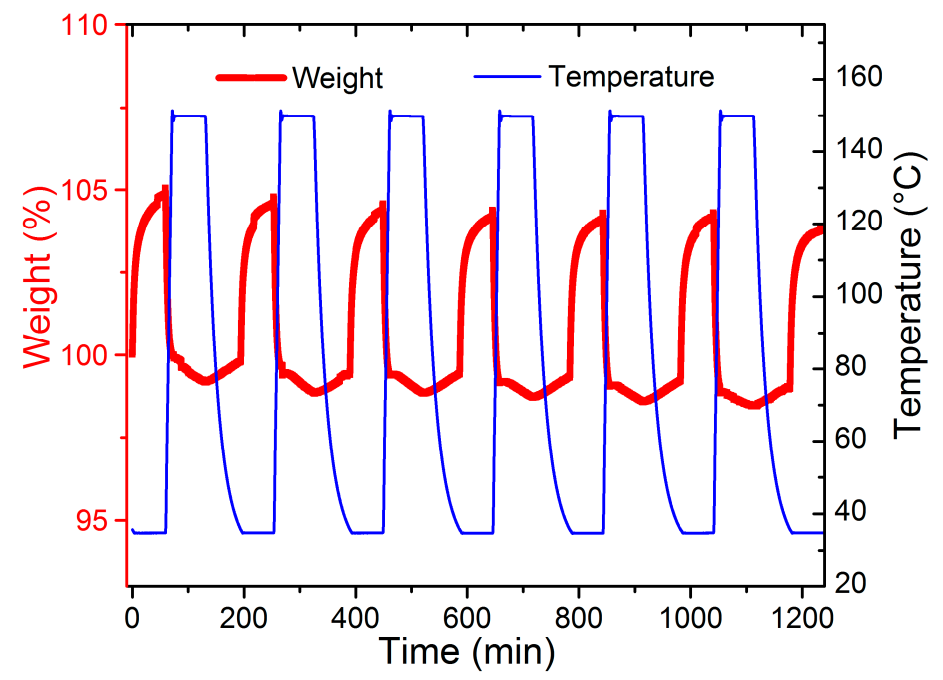

Figure 6. $\mathrm{CO}_{2}$ adsorption and desorption cycle of MIP-207- $\mathrm{NH}_{2}-25 \%$.

The results of the dynamic $\mathrm{CO}_{2} / \mathrm{N}_{2}$ adsorption of both MIP-207- $\mathrm{NH}_{2}-25 \%$ and MIP207 (as a comparison) are shown in Figure 7. There was an obvious difference in breakthrough time between $\mathrm{CO}_{2}$ and $\mathrm{N}_{2}$ under different gas flow rates. After an initial period where the $\mathrm{N}_{2}$ and $\mathrm{CO}_{2}$ were fully absorbed, the $\mathrm{N}_{2}$ preferentially penetrated the adsorption bed, followed by the $\mathrm{CO}_{2}$. The outlet concentration of $\mathrm{N}_{2}$ exceeded the inlet concentration because $\mathrm{CO}_{2}$ adsorption equilibrium was not reached. Finally, $\mathrm{CO}_{2}$ began to be eluted and the concentration of $\mathrm{N}_{2}$ and $\mathrm{CO}_{2}$ gradually reached the feed concentration value $\left(c / c_{0}=1\right)$, indicating that the adsorption bed was saturated. The interval of breakthrough time between $\mathrm{CO}_{2}$ and $\mathrm{N}_{2}$ in MIP-207- $\mathrm{NH}_{2}-25 \%$ was longer than that of MIP-207 at any gas flow rate, especially at $10 \mathrm{sccm}$, which fully demonstrates that MIP-207- $\mathrm{NH}_{2}-25 \%$ has a better dynamic separation performance. The reason is that the electric field of the MIP-207- $-\mathrm{NH}_{2}-25 \%$ framework has the stronger interaction with $\mathrm{CO}_{2}$ due to the presence of LBSs and the hydrogen bond [37,39-41]. Moreover, from Figure 7, MIP-207- $\mathrm{NH}_{2}-25 \%$ has a larger slope than MIP-207 under different gas flow rates, indicating that the mass transfer resistance of gas in MIP-207- $\mathrm{NH}_{2}-25 \%$ is smaller, which is more conducive to gas diffusion and spread. The possible reason for this is that MIP-207- $\mathrm{NH}_{2}-25 \%$ has a larger pore volume. 

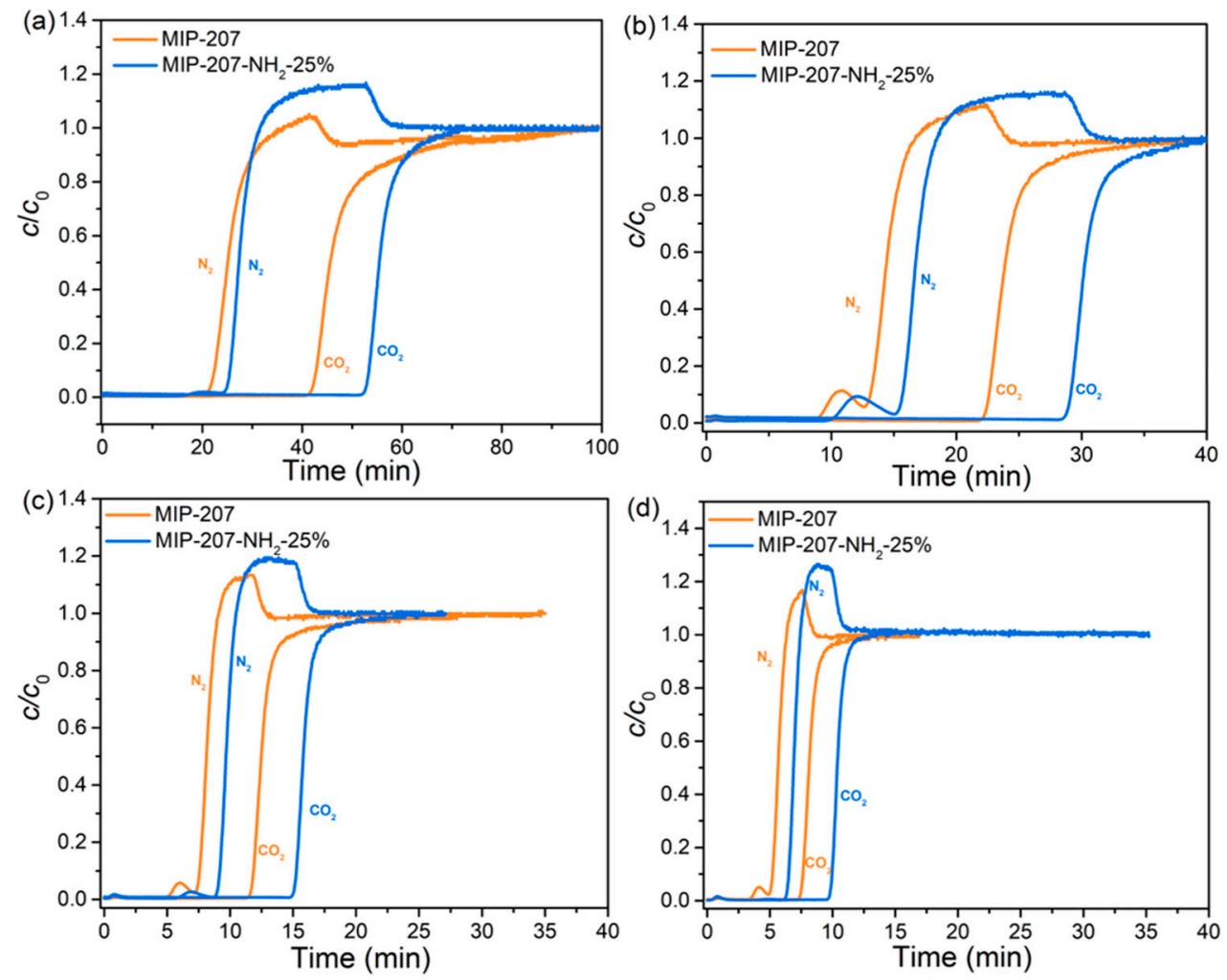

Figure 7. $\mathrm{CO}_{2}$ and $\mathrm{N}_{2}$ breakthrough curves of MIP-207 and MIP-207- $\mathrm{NH}_{2}-25 \%$ at different gas flow rates: (a) $10 \mathrm{sccm},($ b) $20 \mathrm{sccm}$, (c) $50 \mathrm{sccm}$, and (d) $100 \mathrm{sccm}$, respectively.

The dynamic equilibrium adsorption capacity and separation factor of both MIP-207 and MIP-207- $\mathrm{NH}_{2}-25 \%$ were calculated based on previous reports [34,42]. As shown in Figure 8, it can be found that the $\mathrm{CO}_{2}$ equilibrium adsorption capacity of MIP-207- $\mathrm{NH}_{2}$ $25 \%$ was higher than that of MIP-207 under the four mixed gas flow rates (Figure 8a,b). At 10 and $20 \mathrm{sccm}$, the $\mathrm{CO}_{2} / \mathrm{N}_{2}$ separation factors of MIP-207- $\mathrm{NH}_{2}-25 \%$ were 2.36 and 2.03, which were higher than the 2.01 and 1.93 of MIP-207, respectively. The difference of separation factors between MIP-207 and MIP-207- $\mathrm{NH}_{2}-25 \%$ cannot be clearly observed at the mixture gas flow rates of 50 and $100 \mathrm{sccm}$ (Figure $8 \mathrm{a}, \mathrm{b}$ ). This is because the residence time of gas in the adsorption bed decreases with the increase of flow rate.
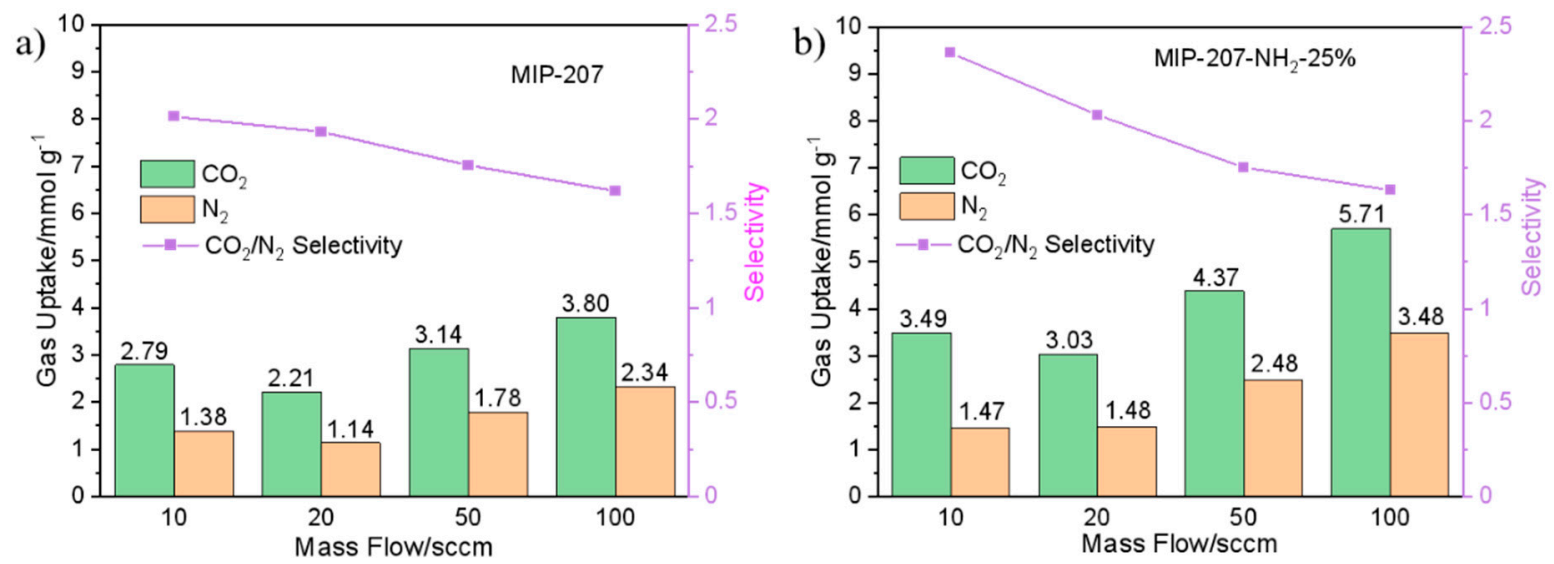

Figure 8. Dynamic $\mathrm{CO}_{2}$ and $\mathrm{N}_{2}$ adsorption and separation performance of (a) MIP-207 and (b) MIP-207-NH $-25 \%$. 


\section{Conclusions}

In summary, the amine-modified highly stable MIP-207 with different $-\mathrm{NH}_{2}$ content was successfully prepared by the mixed linkers method. The texture and structure framework of the original MIP-207 were maintained in the MIP-207- $\mathrm{NH}_{2}-n(n=15 \%, 25 \%$, $50 \%$ ) composites. The $\mathrm{CO}_{2}$ adsorption and breakthrough experiments show that MIP207- $\mathrm{NH}_{2}-25 \%$ demonstrates the superior $\mathrm{CO}_{2}$ capture and separation performance. The highly efficient $\mathrm{CO}_{2}$ uptake is attributed to the introduction of $-\mathrm{NH}_{2}$ into the framework of MIP-207, leading to the increase of specific surface area and more Lewis basic adsorption sites, thereby enhancing the $\mathrm{CO}_{2}$ working capacity and $\mathrm{CO}_{2} / \mathrm{N}_{2}$ selectivity. This work provides an additional avenue to prepare highly stable amine-functionalized MOFs for high efficiency $\mathrm{CO}_{2}$ capture.

Supplementary Materials: The following are available online at https:/ /www.mdpi.com/article/ 10.3390/nano11123348/s1, Figure S1: PXRD patterns of MIP-207 and MIP-207 after activation at $150{ }^{\circ} \mathrm{C}$. Figure S2: PXRD pattern of MIP-207-NH $\mathrm{N}_{2}-100 \%$. Figure S3: SEM images of $(\mathbf{a}, \mathbf{b})$ MIP-207, (c) MIP-207- $\mathrm{NH}_{2}-15 \%$, (d) MIP-207- $\mathrm{NH}_{2}-25 \%$, (e) MIP-207- $\mathrm{NH}_{2}-50 \%$, and (f) MIP-207- $\mathrm{NH}_{2}-60 \%$. Figure S4: The pore size distribution curves of MIP-207. Figure S5: $\mathrm{N}_{2}$ adsorption and desorption isotherms of MIP-207- $\mathrm{NH}_{2}-100 \%$. Figure S6: The relationship of between $\mathrm{CO}_{2} / \mathrm{N}_{2}$ adsorption and specific surface area of samples. Table S1: The BET data of MIP-207- $\mathrm{NH}_{2}-100 \%$.

Author Contributions: Data curation, Y.W. (Yinji Wan), Y.M., D.K., Y.W. (Yingxiao Wu) and J.S.; formal analysis, Y.W. (Yinji Wan); funding acquisition, R.Z. (Ruiqin Zhong) and R.Z. (Ruqiang Zou); investigation, T.Q. and Q.Z.; methodology, T.Q.; resources, R.Z. (Ruqiang Zou); supervision, R.Z. (Ruiqin Zhong); writing—original draft, Y.W. (Yinji Wan); writing—review and editing, R.Z. (Ruiqin Zhong) and R.Z. (Ruqiang Zou). All authors have read and agreed to the published version of the manuscript.

Funding: This research was funded by the National Natural Science Foundation of China, grant numbers 51772329 and 51972340.

Data Availability Statement: All data are available upon reasonable request.

Acknowledgments: The authors extend much thanks to the reviewers for their valuable suggestions that have helped improve our paper substantially.

Conflicts of Interest: The authors declare no conflict of interest.

\section{References}

1. Haszeldine, R.S. Carbon Capture and Storage: How Green Can Black Be? Science 2009, 325, 1647-1652. [CrossRef] [PubMed]

2. Boyd, P.G.; Chidambaram, A.; Garcia-Diez, E.; Ireland, C.P.; Daff, T.D.; Bounds, R.; Gladysiak, A.; Schouwink, P.; Moosavi, S.M.; Maroto-Valer, M.M.; et al. Data-driven design of metal-organic frameworks for wet flue gas $\mathrm{CO}_{2}$ capture. Nature 2019, 576, 253-256. [CrossRef] [PubMed]

3. Sovacool, B.K.; Griffiths, S.; Kim, J.; Bazilian, M. Climate change and industrial F-gases: A critical and systematic review of developments, sociotechnical systems and policy options for reducing synthetic greenhouse gas emissions. Renew. Sustain. Energy Rev. 2021, 141, 110759. [CrossRef]

4. Chao, C.; Deng, Y.M.; Dewil, R.; Baeyens, J.; Fan, X.F. Post-combustion carbon capture. Renew. Sustain. Energy Rev. 2021, $138,19$. [CrossRef]

5. Zeng, Y.; Zou, R.; Zhao, Y. Covalent Organic Frameworks for $\mathrm{CO}_{2}$ Capture. Adv. Mater. 2016, 28, 2855-2873. [CrossRef] [PubMed]

6. Younas, M.; Rezakazemi, M.; Daud, M.; Wazir, M.B.; Ahmad, S.; Ullah, N.; Inamuddin; Ramakrishna, S. Recent progress and remaining challenges in post-combustion $\mathrm{CO}_{2}$ capture using metal-organic frameworks (MOFs). Prog. Energy Combust. Sci. 2020, 80, 100849. [CrossRef]

7. Samanta, A.; Zhao, A.; Shimizu, G.K.H.; Sarkar, P.; Gupta, R. Post-Combustion $\mathrm{CO}_{2}$ Capture Using Solid Sorbents: A Review. Ind. Eng. Chem. Res. 2012, 51, 1438-1463. [CrossRef]

8. D'Alessandro, D.M.; Smit, B.; Long, J.R. Carbon dioxide capture: Prospects for new materials. Angew. Chem. Int. Ed. 2010, 49, 6058-6082. [CrossRef]

9. Wei, Y.S.; Zhang, M.; Zou, R.; Xu, Q. Metal-Organic Framework-Based Catalysts with Single Metal Sites. Chem. Rev. 2020, 120, 12089-12174. [CrossRef]

10. Zou, R.; Li, P.-Z.; Zeng, Y.-F.; Liu, J.; Zhao, R.; Duan, H.; Luo, Z.; Wang, J.-G.; Zou, R.; Zhao, Y. Bimetallic Metal-Organic Frameworks: Probing the Lewis Acid Site for $\mathrm{CO}_{2}$ Conversion. Small 2016, 12, 2334-2343. [CrossRef]

11. Li, H.; Wang, K.; Sun, Y.; Lollar, C.T.; Li, J.; Zhou, H.-C. Recent advances in gas storage and separation using metal-organic frameworks. Mater. Today 2018, 21, 108-121. [CrossRef] 
12. Furukawa, H.; Cordova, K.E.; O’Keeffe, M.; Yaghi, O.M. The Chemistry and Applications of Metal-Organic Frameworks. Science 2013, 341, 1230444. [CrossRef]

13. Zhou, H.-C.; Long, J.R.; Yaghi, O.M. Introduction to Metal-Organic Frameworks. Chem. Rev. 2012, 112, 673-674. [CrossRef] [PubMed]

14. Bose, P.; Bai, L.; Ganguly, R.; Zou, R.; Zhao, Y. Rational Design and Synthesis of a Highly Porous Copper-Based Interpenetrated Metal-Organic Framework for High $\mathrm{CO}_{2}$ and $\mathrm{H}_{2}$ Adsorption. ChemPlusChem 2015, 80, 1259-1266. [CrossRef]

15. Zheng, B.; Bai, J.; Duan, J.; Wojtas, L.; Zaworotko, M.J. Enhanced $\mathrm{CO}_{2}$ Binding Affinity of a High-Uptake rht-Type Metal-Organic Framework Decorated with Acylamide Groups. J. Am. Chem. Soc. 2011, 133, 748-751. [CrossRef]

16. Hong, D.-Y.; Hwang, Y.K.; Serre, C.; Ferey, G.; Chang, J.-S. Porous Chromium Terephthalate MIL-101 with Coordinatively Unsaturated Sites: Surface Functionalization, Encapsulation, Sorption and Catalysis. Adv. Funct. Mater. 2009, 19, 1537-1552. [CrossRef]

17. Trickett, C.A.; Helal, A.; Al-Maythalony, B.A.; Yamani, Z.H.; Cordova, K.E.; Yaghi, O.M. The chemistry of metal-organic frameworks for $\mathrm{CO}_{2}$ capture, regeneration and conversion. Nat. Rev. Mater. 2017, 2, 17045. [CrossRef]

18. Ding, M.; Flaig, R.W.; Jiang, H.-L.; Yaghi, O.M. Carbon capture and conversion using metal-organic frameworks and MOF-based materials. Chem. Soc. Rev. 2019, 48, 2783-2828. [CrossRef]

19. Martinez, F.; Sanz, R.; Orcajo, G.; Briones, D.; Yangueez, V. Amino-impregnated MOF materials for $\mathrm{CO}_{2}$ capture at postcombustion conditions. Chem. Eng. Sci. 2016, 142, 55-61. [CrossRef]

20. Kong, L.; Zou, R.; Bi, W.; Zhong, R.; Mu, W.; Liu, J.; Han, R.P.S.; Zou, R. Selective adsorption of $\mathrm{CO}_{2} / \mathrm{CH}_{4}$ and $\mathrm{CO}_{2} / \mathrm{N}_{2}$ within a charged metal-organic framework. J. Mater. Chem. A 2014, 2, 17771-17778. [CrossRef]

21. Zhu, J.; Li, P.-Z.; Guo, W.; Zhao, Y.; Zou, R. Titanium-based metal-organic frameworks for photocatalytic applications. Coord. Chem. Rev. 2018, 359, 80-101. [CrossRef]

22. Wang, L.; Zou, R.; Guo, W.; Gao, S.; Meng, W.; Yang, J.; Chen, X.; Zou, R. A new microporous metal-organic framework with a novel trinuclear nickel cluster for selective $\mathrm{CO}_{2}$ adsorption. Inorg. Chem. Commun. 2019, 104, 78-82. [CrossRef]

23. Wang, Q.; Xia, W.; Guo, W.; An, L.; Xia, D.; Zou, R. Functional Zeolitic-Imidazolate-Framework-Templated Porous Carbon Materials for $\mathrm{CO}_{2}$ Capture and Enhanced Capacitors. Chem. Eur. J. 2013, 8, 1879-1885. [CrossRef]

24. Xiang, Z.; Hu, Z.; Cao, D.; Yang, W.; Lu, J.; Han, B.; Wang, W. Metal-Organic Frameworks with Incorporated Carbon Nanotubes: Improving Carbon Dioxide and Methane Storage Capacities by Lithium Doping. Angew. Chem. Int. Ed. 2011, 50, 491-494. [CrossRef]

25. Ma, S.; Sun, D.; Simmons, J.M.; Collier, C.D.; Yuan, D.; Zhou, H.-C. Metal-organic framework from an anthracene derivative containing nanoscopic cages exhibiting high methane uptake. J. Am. Chem. Soc. 2008, 130, 1012-1016. [CrossRef]

26. Sumida, K.; Rogow, D.L.; Mason, J.A.; McDonald, T.M.; Bloch, E.D.; Herm, Z.R.; Bae, T.-H.; Long, J.R. Carbon Dioxide Capture in Metal-Organic Frameworks. Chem. Rev. 2012, 112, 724-781. [CrossRef]

27. Cao, L.Y.; Lin, Z.K.; Peng, F.; Wang, W.W.; Huang, R.Y.; Wang, C.; Yan, J.W.; Liang, J.; Zhang, Z.M.; Zhang, T.; et al. Self-Supporting Metal-Organic Layers as Single-Site Solid Catalysts. Angew. Chem. Int. Ed. 2016, 55, 4962-4966. [CrossRef]

28. Kim, E.J.; Siegelman, R.L.; Jiang, H.Z.H.; Forse, A.C.; Lee, J.-H.; Martell, J.D.; Milner, P.J.; Falkowski, J.M.; Neaton, J.B.; Reimer, J.A.; et al. Cooperative carbon capture and steam regeneration with tetraamine-appended metal-organic frameworks. Science 2020, 369, 392-396. [CrossRef] [PubMed]

29. Zhong, R.; Yu, X.; Meng, W.; Han, S.; Liu, J.; Ye, Y.; Sun, C.; Chen, G.; Zou, R. A solvent 'squeezing' strategy to graft ethylenediamine on $\mathrm{Cu}_{3}(\mathrm{BTC})_{2}$ for highly efficient $\mathrm{CO}_{2} / \mathrm{CO}$ separation. Chem. Eng. Sci. 2018, 184, 85-92. [CrossRef]

30. Bae, Y.S.; Farha, O.K.; Hupp, J.T.; Snurr, R.Q. Enhancement of $\mathrm{CO}_{2} / \mathrm{N}_{2}$ selectivity in a metal-organic framework by cavity modification. J. Mater. Chem. 2009, 19, 2131-2134. [CrossRef]

31. Han, G.; Qian, Q.H.; Rodriguez, K.M.; Smith, Z.P. Hydrothermal Synthesis of Sub-20 nm Amine-Functionalized MIL-101(Cr) Nanoparticles with High Surface Area and Enhanced $\mathrm{CO}_{2}$ Uptake. Ind. Eng. Chem. Res. 2020, 59, 7888-7900. [CrossRef]

32. Zhong, R.; Yu, X.; Meng, W.; Liu, J.; Zhi, C.; Zou, R. Amine-Grafted MIL-101(Cr) via Double-Solvent Incorporation for Synergistic Enhancement of $\mathrm{CO}_{2}$ Uptake and Selectivity. ACS Sustain. Chem. Eng. 2018, 6, 16493-16502. [CrossRef]

33. Wang, S.; Reinsch, H.; Heymans, N.; Wahiduzzaman, M.; Martineau-Corcos, C.; De Weireld, G.; Maurin, G.; Serre, C. Toward a Rational Design of Titanium Metal-Organic Frameworks. Matter 2020, 2, 440-450. [CrossRef]

34. Zhong, R.; Liu, J.; Huang, X.; Yu, X.; Sun, C.; Chen, G.; Zou, R. Experimental and theoretical investigation of a stable zinc-based metal-organic framework for $\mathrm{CO}_{2}$ removal from syngas. CrystEngComm 2015, 17, 8221-8225. [CrossRef]

35. Gandara, F.; Furukawa, H.; Lee, S.; Yaghi, O.M. High methane storage capacity in aluminum metal-organic frameworks. J. Am. Chem. Soc. 2014, 136, 5271-5274. [CrossRef] [PubMed]

36. Darunte, L.A.; Oetomo, A.D.; Walton, K.S.; Sholl, D.S.; Jones, C.W. Direct Air Capture of $\mathrm{CO}_{2}$ Using Amine Functionalized MIL-101(Cr). ACS Sustain. Chem. Eng. 2016, 4, 5761-5768. [CrossRef]

37. Lin, Y.; Lin, H.; Wang, H.; Suo, Y.; Li, B.; Kong, C.; Chen, L. Enhanced selective $\mathrm{CO}_{2}$ adsorption on polyamine/MIL-101(Cr) composites. J. Mater. Chem. A 2014, 2, 14658-14665. [CrossRef]

38. Liao, P.-Q.; Zhou, D.-D.; Zhu, A.-X.; Jiang, L.; Lin, R.-B.; Zhang, J.-P.; Chen, X.-M. Strong and Dynamic $\mathrm{CO}_{2}$ Sorption in a Flexible Porous Framework Possessing Guest Chelating Claws. J. Am. Chem. Soc. 2012, 134, 17380-17383. [CrossRef] 
39. Yoo, D.K.; Yoon, T.U.; Bae, Y.S.; Jhung, S.H. Metal-organic framework MIL-101 loaded with polymethacrylamide with or without further reduction: Effective and selective $\mathrm{CO}_{2}$ adsorption with amino or amide functionality. Chem. Eng. J. 2020, $380,122496$. [CrossRef]

40. Ding, R.; Zheng, W.; Yang, K.; Dai, Y.; Ruan, X.; Yan, X.; He, G. Amino-functional ZIF-8 nanocrystals by microemulsion based mixed linker strategy and the enhanced $\mathrm{CO}_{2} / \mathrm{N}_{2}$ separation. Sep. Purif. Technol. 2020, 236, 116209. [CrossRef]

41. Zhang, M.; Guo, Y. Rate based modeling of absorption and regeneration for $\mathrm{CO}_{2}$ capture by aqueous ammonia solution. Appl. Energy 2013, 111, 142-152. [CrossRef]

42. Xiang, S.; He, Y.; Zhang, Z.; Wu, H.; Zhou, W.; Krishna, R.; Chen, B. Microporous metal-organic framework with potential for carbon dioxide capture at ambient conditions. Nat. Commun. 2012, 3, 954. [CrossRef] [PubMed] 